\title{
Application of Digital Image Processing Techniques to Geological and Geomorphological Features of Southwest Jordan
}

\author{
M. S. Al-Shumaimri \\ Dept. of Earth and Environmental Sciences, Faculty of Science, Kuwait University \\ P.O.Box 5969 Safat-13060, State of Kuwait \\ E-mail: selrabaa@hotmail.com
}

Received: October 8, 2011 Accepted: November 4, $2011 \quad$ Published: March 1, 2012

doi:10.5539/jgg.v4n1p41 URL: http://dx.doi.org/10.5539/jgg.v4n1p41

\begin{abstract}
A Landsat image of the multispectral scanner system covering an area lying between the Aqabah Gulf and the southern margin of the Dead Sea was analyzed by digital image processing techniques to delineate various geological and structural features of southwest Jordan area. Two major techniques in digital image processing were employed. They are preprocessing and enhancement, and their constituent treatment processes. Types of lithology, lineaments and topographic contrasts of southwest Jordan were used as test criteria. Results of comparison indicate that the combination of images processed by first principal component, second principal component and filtered first principal component as assigned to the hue, saturation and intensity system coordinates, respectively, provided better results than products of other digital techniques. Such good results enable geologists to map major lithologies, lineaments and other structural features effectively, as well as to assess topographic variations.
\end{abstract}

Keywords: Digital image processing, Landsat, Lineaments, Southwest Jordan

\section{Introduction}

This study deals with evaluation of digital processing techniques over a large area in southwest Jordan, extending westward from western parts of the areas of Wadi Al-Arabah to Al-Jafr basin and northward from the Dead Sea-Wadi Al-Hassa line to the Saudi-Arabia boundary (Figure 1). This area is covered by a Landsat image that was launched on March 5, 1978. Information on the study area was recorded by the multi spectral scanner system (Siegal \& Gillespie, 1980). The image was obtained as a computer-compatible tape (CCT) and covers an area of approximately $185 \times 185 \mathrm{~km}^{2}$. This coverage lies on row number 39 and path number 187 (Scene ID: 83028907322).

The main objective of the present study is to delineate the structural features of the southwest Jordan image. Figure 2 shows the major structural features of the study area. Indeed, application of remote sensing techniques for the study of regional tectonics is more valuable than other applications in geology (Sabins, 1978). Wise et al. (1985) demonstrate that the digital image processing techniques are useful for studying regional tectonic features.

Previously, the selected area and the surroundings were studied by utilizing digital image analysis by a number of researchers. Berlin et al. (1976) studied digital data extracted from a Landsat MSS image representing the southern part of the study area to demonstrate geologic applications of MSS images in an arid environment. The lithologic units were easily identified in their resulting enhanced images, but the structural features were not described, leading to their suggestion that their analyses need to be revised using the geologic maps of Jordan produced by Bender (1974 and 1975). Edwards et al. (1999), Tansey et al. (1999) and Al-Bakri and Taylor (2003) utilized satellite imaging data to map and monitor the changes in the vegetation and the soil moisture of different areas in Jordan. Rawashdeh et al. (2006) used remote sensing techniques in geological studies in El-Azraq area, Jordan. Chung et al. (2008) proposed algorithm for color contrast enhancement.

\section{Application of Image Processing Techniques to Southwest Jordan}

The Landsat MSS image of the study area was analyzed by digital image processing techniques that employ the High Level Image system. Figure 2 demonstrates the selected areas for enhancement techniques. 
The techniques, commonly employing digital image processes which are preprocessing and enhancement system, were performed in the present study. However data interpretation was made through use of enhanced products.

\subsection{Preprocessing}

A radiometric defect in the southwest Jordan image, in which there was an offset by 6 rows, was observed on column 2395 in each band. A small program was developed to correct this defect. The corrected band images were adjusted by additional new rows at the lower right (southwest) corner.

The image is also rectified geometrically by using the nearest neighbor interpolation procedure, described by Bernstein (1976) and Curran (1985).

Once these corrections are made, the corrected data are then used in further steps of data analysis to image enhancement techniques.

\subsection{Image Enhancement}

The procedures used in this study are contrast stretching, ratioing, principal component transformation, high-pass filtering and application of a color coordinate system.

\subsection{Contrast Stretching}

Two types of contrast enhancement were applied to the southwest Jordan image-linear and nonlinear stretching.

The brightness values of the original image lie within a very small range of the grey level. Thus, features in the scene were not easily distinguished because of the very low scene contrast. Contrast among morphological features in the image, expanded by linear stretch (Figure 3) was more clearly visible than in the original one. In areas underlain by contrasting rocks, such as east of Wadi Arabah, the linear stretch method produced subtle differences in tones among different rocks (i.e. basement, Phanerozoic cover and alluvial deposits). Linear contrast stretch reduces contrast among similar lithological units, such as different granitic units in the basement, while increasing contrast between sedimentary and crystalline rocks over the whole area. Many forms of Quaternary sediments, including wadi fill and alluvial fans of various geological time scale were readily distinguishable. Recent fans adjacent to the Wadi Arabah escarpment acquired distinctive brownish tones in the linear contrast enhanced image. As older fans suffered first from reworking and then were covered by sand dunes, their tones appear light blue in the image and can be easily separated from younger fans. On the other hand, it was observed that the non-linear stretch techniques accentuate subtle differences among drainage patterns, especially gullies in the Al-Jafr basin. However, brightness differences among lithological units (i.e., basement and Phanerozoic cover) are indistinguishable in this type of stretch.

\subsection{Ratioing}

Ratioing applied to southwest Jordan image tends to play a minor role in geologic and structural interpretation. The resulted ratioed image (Figure 4) minimizes the influence of the relief, thus enhancing the actual spectral reflection of the surface areas. Elevation contrast is well distinguished in this product, for example at the southwestern parts of the studied area. Besides, it produced a notably higher brightness value for the basement than for other lithological types.

\subsection{Principal Components}

Principal component analysis identified the dominant first and second, represented by PC1 (85\%) and PC2. The first principal component utilizes data from all four spectral bands (4, 5, 6 and 7) (kwarteng and Chavez, 1998). The PC1 image is expected to have more significant geomorphological and geological information, than the PC2 image (Berhe and Rothery, 1986). PC1 shows lithology, topography and structural features well, including lineaments and domal structures which became more pronounced in the image of southwest Jordan.

\subsection{High Pass Filtering}

Filtered images are the best in delineating the lineaments; however they are generally of less use for the purposes of lithological differences. So, high pass filtering technique is applied to the first principal component image to obtain better results. This has been generated by utilizing different kernel sizes that were tried to process the image under study: $3 \times 3,5 \times 5,7 \times 7$ and $9 \times 9$ pixels. The optimum kernel size which provides the best results depending on the quality of the image is obtained by using $3 \times 3$ kernel of the form:

$\begin{array}{lll}-1 & -1 & -1 \\ -1 & -9 & -1 \\ -1 & -1 & -1\end{array}$


Figure 5 shows the filtered first principal component image produced by this kernel. The contrast increases and the features appear sharp. Drainage and structural features, particularly lineaments are best enhanced by this technique. Solid-drift boundaries also appear sharp. Stream courses, as well as the shoreline of the Aqabah Gulf, become very clear. Streams following lineaments, which normally appear white in other products, show as fine, narrow and crisp lines in this image. Lineaments defining contrasts between lithologies showing comparable tones on either side, such as Ras En-Naqb escarpment and Al-Quwairah lineament, appear well represented. Additionally, sharp lines delineating domal and fold structures affecting sediments on the western side of the Wadi Arabah are easily detected.

\subsection{Color Coordinates System}

The color coordinate system IHS (intensity, hue and saturation) is applied to the resulted images: PC1, PC2, and FPC1 (Filtered PC1) to get the best product that emphasizes the contents of the image. Each pixel in the image of the first principal component (PC1), second principal component (PC2) and filtered first principal component (FPC1) is assigned a value for each of the three coordinates $\mathrm{H}, \mathrm{S}$, and I, respectively, to obtain an image with visually better contrast. The resulted image was obtained after several trials were conducted with the assignment of the IHS coordinates to the aforementioned images. Figure 6 illustrates the best color display of southwest Jordan image that has resulted from this assignment. It emphasizes the lithological, structural and topographic contrast in color, which is suitable for visual interpretation and helps in discrimination among areas of only slightly different spectral responses. Other applied assignments, although they yield better contrast in areas of high reflectance, such as those covered by Quaternary sediments, lead to loss of some significant lineaments in the basement. However, the quality of Figure 6 aids in detecting most of the lineaments, especially when the resulted image is further subjected to linear contrast stretching.

\section{Discussion}

Results of the application of the digital analysis to the southwest Jordan Landsat MSS image indicate that computer processing techniques provide useful information on geological and landform patterns in southwest Jordan. Lillesand and Kiefer (1979), Al-Mokredi et al. (2007) and Raharimahefa and Kusky (2009) demonstrated how remote sensing data could be useful for mapping and extraction of the structural features. A comparison has been made among different enhanced products obtained in this study to determine their capabilities in delineating various geological features (Table 1). In this evaluation process, the quality of each enhanced products is expressed in order of decreasing capability as good, fair or poor. For this comparison three major types of lithology were selected for evaluation. Referring to the map (Figure 1), they are crystalline basement, sedimentary rock cover and alluvial deposits. Lineaments and topographic contrasts were also used as test criteria. Results of the comparison indicate that the image processed by PC1, PC2, and FPC1 assigned to the HSI system respectively, and then subjected to linear contrast stretching process, provides the best results when compared with other enhanced products. Such images were used for accentuating contrasts for visual inspection of lineaments and differences among lithological units, despite the possibility that some other properties of the images may be inferior to their counterparts of other products. Contrast stretched and ratioed image products were found suitable only for limited and particular purposes. Linear contrast stretching for example, produces image showing differences in geomorphological expressions, but poorly defines lineaments. The ratioed image is reliable for distinguishing between the basement rocks and the overlying sedimentary cover in arid regions, as Offield et al. (1977) and Rawashdeh et al. (2006) mentioned in their study. However, it is still poor in lineament discrimination.

\section{Conclusions}

A Landsat MSS image of southwest Jordan was analyzed by digital image processing techniques employing a high-level image processing system, in an attempt to generate the most appropriate enhancement for lineament mapping. Application of digital analysis techniques to the image of southwest Jordan facilitates corrections of geometric and radiometric distortion and in image enhancement for the detection and extraction of the structural features in southwest Jordan and the nearby countries. Digital image processing technique is very much useful to interpret the lineaments from imageries. The lineaments are well interpreted. The enhancement techniques performed, include contrast stretching, ratioing, filtering, principal component transformation and color display system. Contrast stretching and ratioed images appear to be most useful in distinguishing the topographic and elevation features. Filtered images are the best in delineating the lineaments; however, they are generally of less use for purposes of lithological discrimination. Nevertheless, the quality of this image can be improved if it is combined with the first principal component.

Among these enhancement techniques, the most significant is the combination of first principal component, 
second principal component and filtered first principal component, and their assignment to the HSI coordinates, respectively. Linear contrast stretching process provides the best possible image, through stronger accentuation of contrast for visual inspection of lineaments, structures, lithological contacts, and topographic features.

Consequently, the resulted image enables the geologists to map major lithologies, lineaments and other structural features, as well as to assess topographic variations, effectively.

\section{Acknowledgements}

I would like to thank Dr. A Kamel, M. F. Meree and Dr. T. Al-Atassi of the Kuwait Institute of Scientific Research (KISR) for their fruitful assistance during the analysis of computer processed Landsat data. I also extend my thanks to Professor Divi of Kuwait University for providing constructive comments on the manuscript.

\section{References}

Al-Bakri, J. T. \& Taylor, J. C. (2003). Application of NOAA AVHRR for monitoring vegetation conditions and biomass in Jordan. Journal of Arid Environments, 54(3), 579-593. http://dx.doi.org/10.1006/jare.2002.1081

Al-Mokredi, M. S., Guangdao H., \& Ai-Bassam B. (2007). Using remote sensing data to delineate the lineaments for hydrothermal mineral prediction in the Heging area northwest Yunnan Province, China. Journal of China University of Geosciences, 18(2), 142-147. http://dx.doi.org/10.1016/S1002-0705(07)60028-4

Bender, F. (1974). Explanatory notes on the geological map of the Wadi Arabah, Jordan (Scale 1: 100,000, 3 sheets). Geol. Jahrb., B10, 3-62.

Bender, F. (1975). Geologic Map of Jordan 1: 250,000. Geol. Surv. Of Fed. Rep. Germany, Hannover.

Berhe, S. M. \& Rothery, D. A., (1986). Interactive Processing of Satellite Images for Structural and Lithological Mapping in Northeast Africa. Geol. Mag., 123, 393-403. http://dx.doi.org/10.1017/S0016756800033495

Berlin, G. L., Chavez, P. S. Jr., Grow, T. E., et al. (1976). Preliminary geologic analysis of southwest Jordan from computer enhanced Landsat image data, proc. Annual meeting: American Society of Photogrammetry (BLL No. 0857, 498), 543-563

Bernstein, R. (1976). Digital image processing of earth observation sensor data. IBM Journal of research and development, 20, 40-57. http://dx.doi.org/10.1147/rd.201.0040

Chung, K., Yang W., \& Yan, W. (2008). Efficient edge preserving algorithm for color contrast enhancement with application to color image segmentation. Journal of Visual Communication and Image Representation, 19(5), 299-310. http://dx.doi.org/10.1016/j.jvcir.2008.02.002

Curran, P. J. (1985). Principales of Remote Sensing. London: Longman.

Edwards, M. C., Wellens, J., \& Al-Eisawi, D. (1999). Monitoring the grazing resource of the Badia region, Jordan, using remote sensing. Applied Geography, 19(4), 385-398. http://dx.doi.org/10.1016/S0143-6228(99)00007-7

Kwarteng, A. Y. \& Chavez, P. S. (1998). Change detection study of Kuwait City and environs using multitemporal Landsat Thematic Mapper data. International Journal of Remote Sensing, 19(9), 1651-1662. http://dx.doi.org/10.1080/014311698215162

Lillesand, T. M., \& Kiefer, R. W. (1979). Remote sensing and image interpretation. New York: John Wily \& Sons. Chichester. Bisbane. Toronto, Singapore.

Offield, T. W., Abbot, E. A., Fillespie, A. R., et al. (1977). Structural mapping on enhanced Landsat images of southern Brazil: Tectonic control of mineralization and speculations on metallogeny. Geophysics, 42, 482-500. http://dx.doi.org/10.1190/1.1440720

Raharimahefa, T., \& Kusky, T. (2009). Structural and remote sensing analysis of the Betsimisaraka Suture in northeastern Madagascar. Gondwana Research, 15(1), 14-27. http://dx.doi.org/10.1016/j.gr.2008.07.004

Rawashdeh, S. A., Saleh, B., \& Hamzah, M. (2006). The use of remote sensing technology in geological investigation and mineral detection in El Azraq-Jordan. CyberGeo, 12(11), 1-22

Sabins, F, F. (1978). Remote sensing: Principals and interpretation. San Francisco: W. H. Freeman.

Siegal, B. S., \& Gillespie, A. R. (eds). (1980). Remote sensing in Geology. New York: Wiley.

Tansey, K. J., Millington, A. C., Battikhi, A. M., et al. (1999). Monitoring soil moisture dynamics using satellite imaging radar in northeastern Jordan. Applied Geography, 19(4), 325-344. 
http://dx.doi.org/10.1016/S0143-6228(99)00009-0

Wise, D. U., Funiciello, R., Parotto, M., et al. (1985). Topographic lineaments swarms. Clues to their origin from domain analysis of Italy. Geological Society of America Bulletin, 96, 952-967. http://dx.doi.org/10.1130/0016-7606(1985)96<952:TLSCTT>2.0.CO;2

Table 1. Comparison between detection and identification capabilities of various computer enhanced products of the southern Jordan image used in this study

\begin{tabular}{|c|c|c|c|c|c|}
\hline $\begin{array}{c}\text { Tested } \\
\text { features }\end{array}$ & $\begin{array}{c}\text { Linear } \\
\text { contrast } \\
\text { stretched } \\
\text { image }\end{array}$ & Ratioed & $\begin{array}{c}\text { High pass } \\
\text { filtered } \\
\text { image }\end{array}$ & $\begin{array}{c}1^{\text {st }} \text { principal } \\
\text { component } \\
\text { (PC1) }\end{array}$ & $\begin{array}{c}\text { Image resulted from combination of } \\
\text { PC1, PC2 and FPC1, assigned to HIS } \\
\text { color system and subjected to linear } \\
\text { contrast stretching }\end{array}$ \\
\hline $\begin{array}{c}\text { Crystalline } \\
\text { basement } \\
\text { rocks }\end{array}$ & Fair & Good & Fair & Fair & Good \\
\hline $\begin{array}{c}\text { Sedimentary } \\
\text { rock cover }\end{array}$ & Good & Good & Fair & Good & Good \\
\hline $\begin{array}{c}\text { Alluvial } \\
\text { deposits }\end{array}$ & Good & Poor & Fair & Good & Good \\
\hline Lineaments & Fair & Fair & Good & Good & Good \\
\hline Topography & Fair & Good & Good & Fair & \\
\hline
\end{tabular}

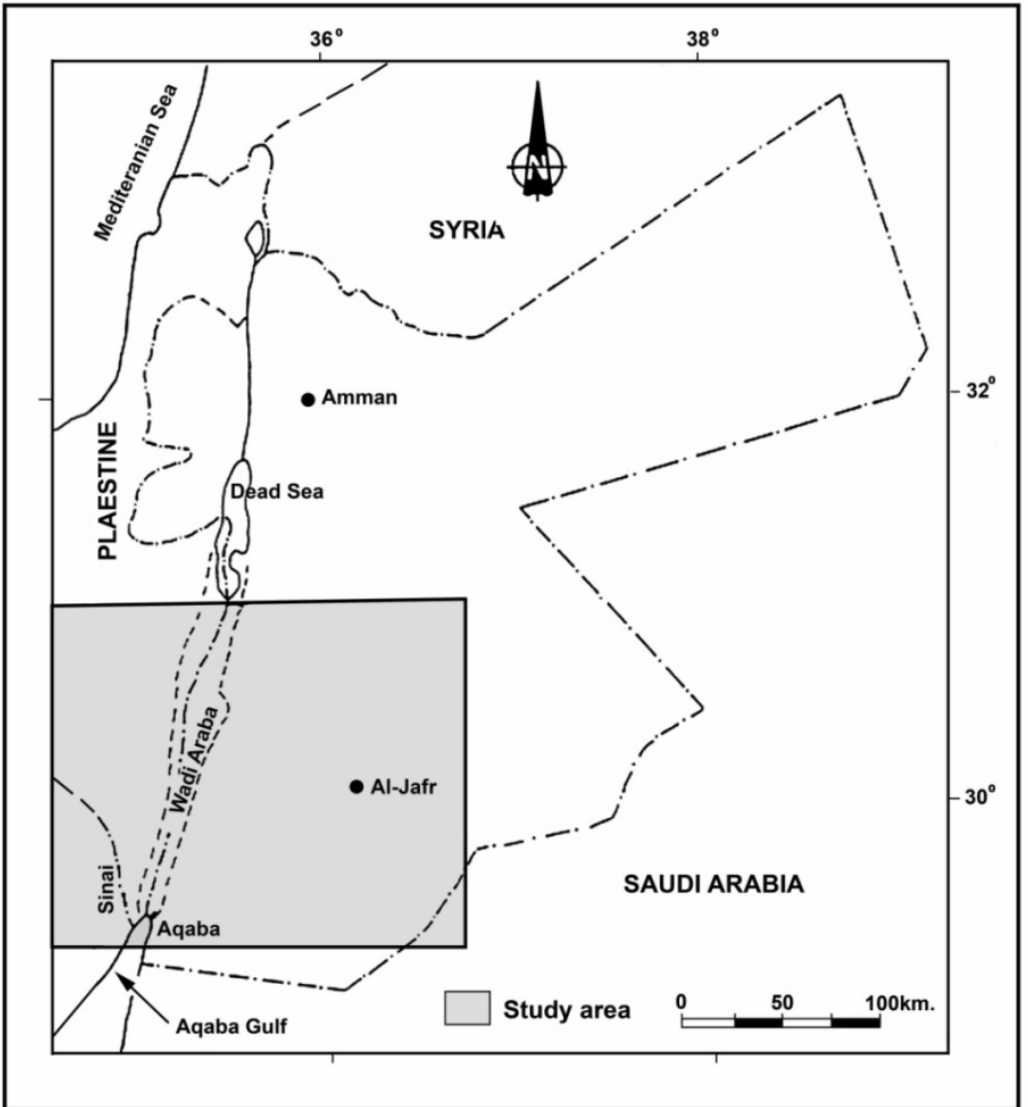

Figure 1. Location map of the Landsat image coverage of the study area 


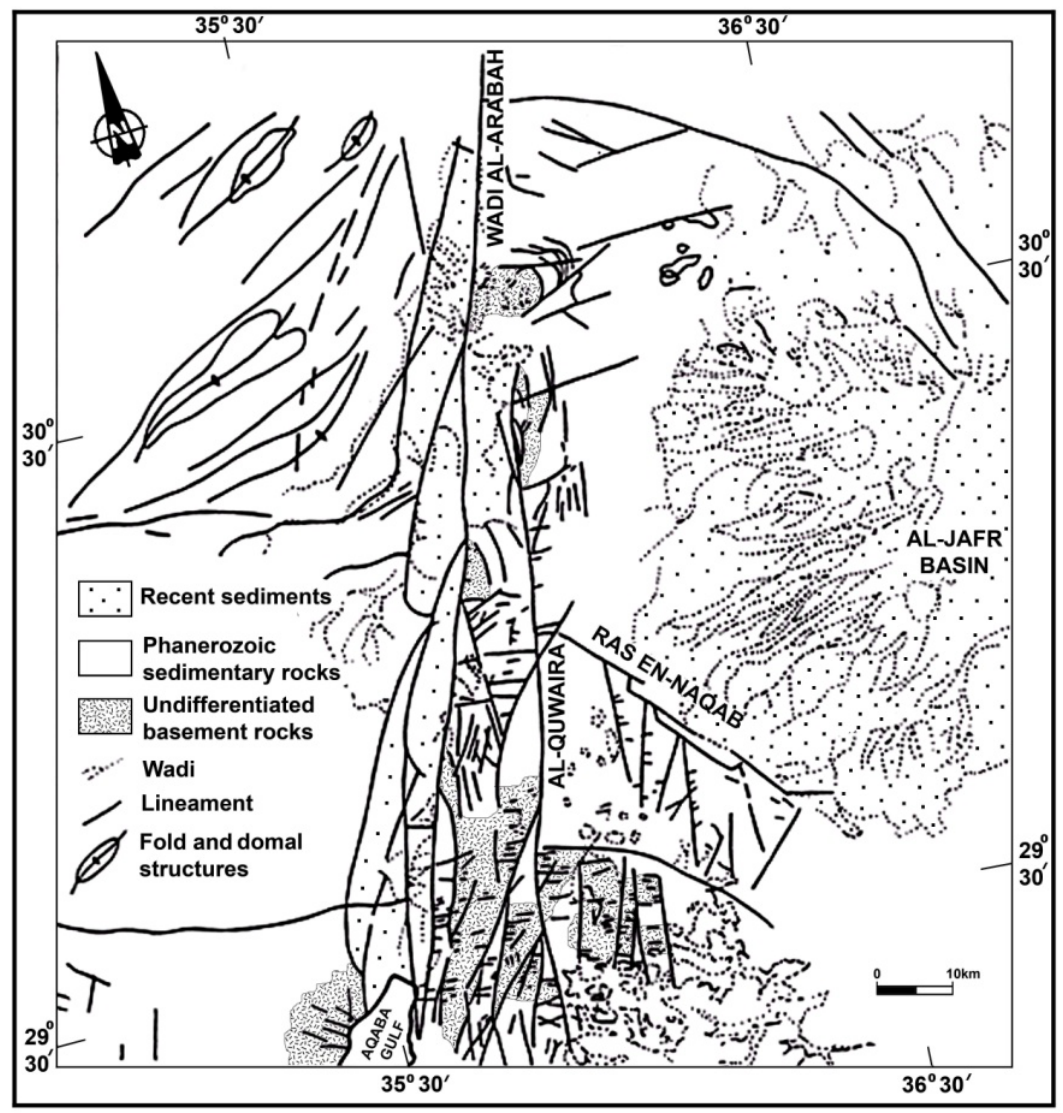

Figure 2. Map of southwest Jordan showing selected areas for enhancement processes

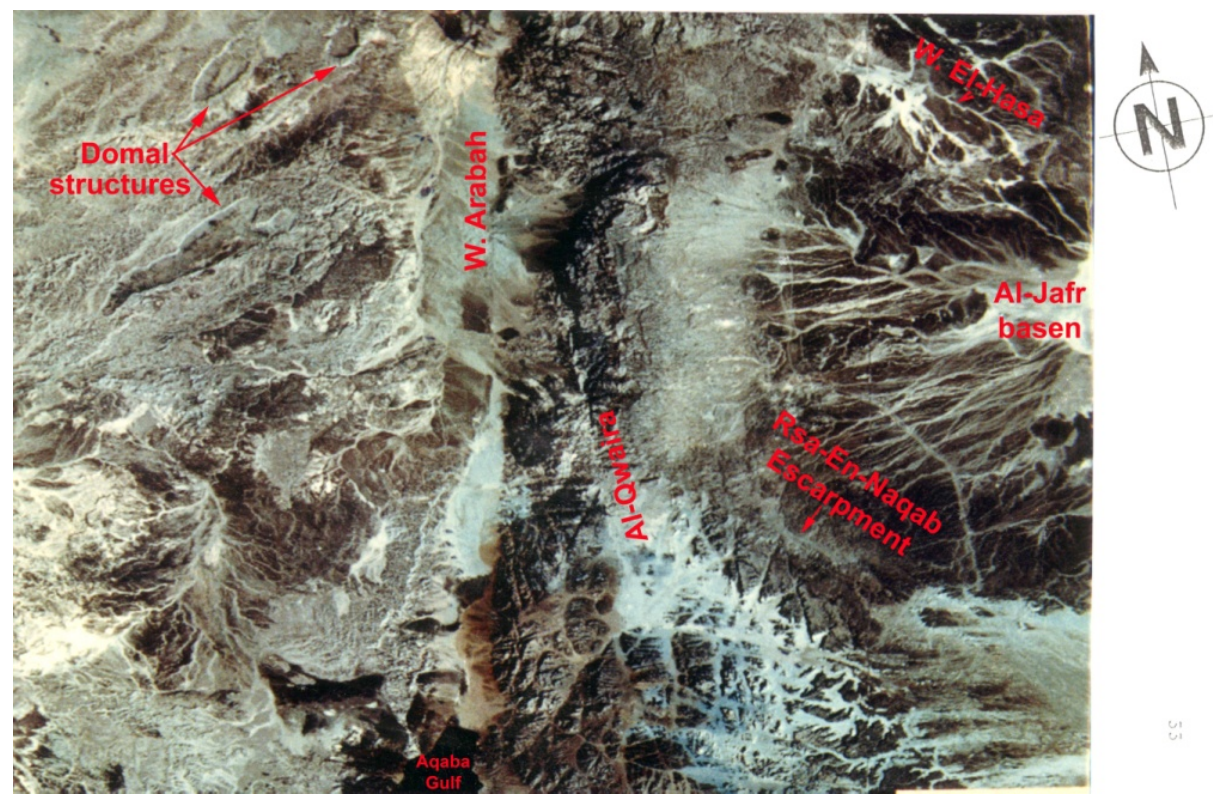

Figure 3. Color composites image of linear contrast stretched images of bands 4, 5and 6 in southwest Jordan 

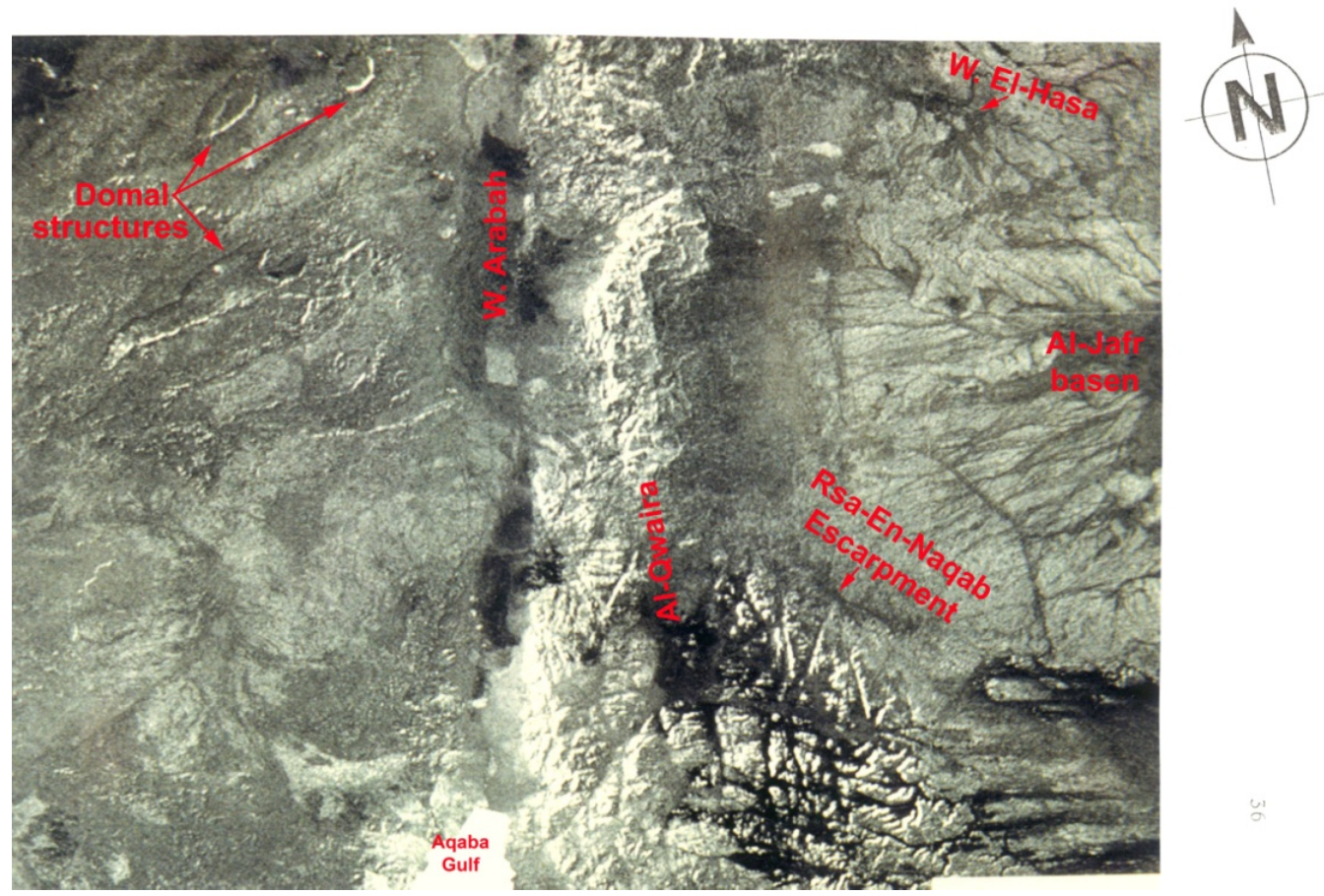

Figure 4. Ratioed image of southwest Jordan. Basement rocks have a notably higher ratioed value (brighter) than other features. Low areas can be identified from the relatively lower brightness values. Highest areas are the brightest and the lowest are the darkest

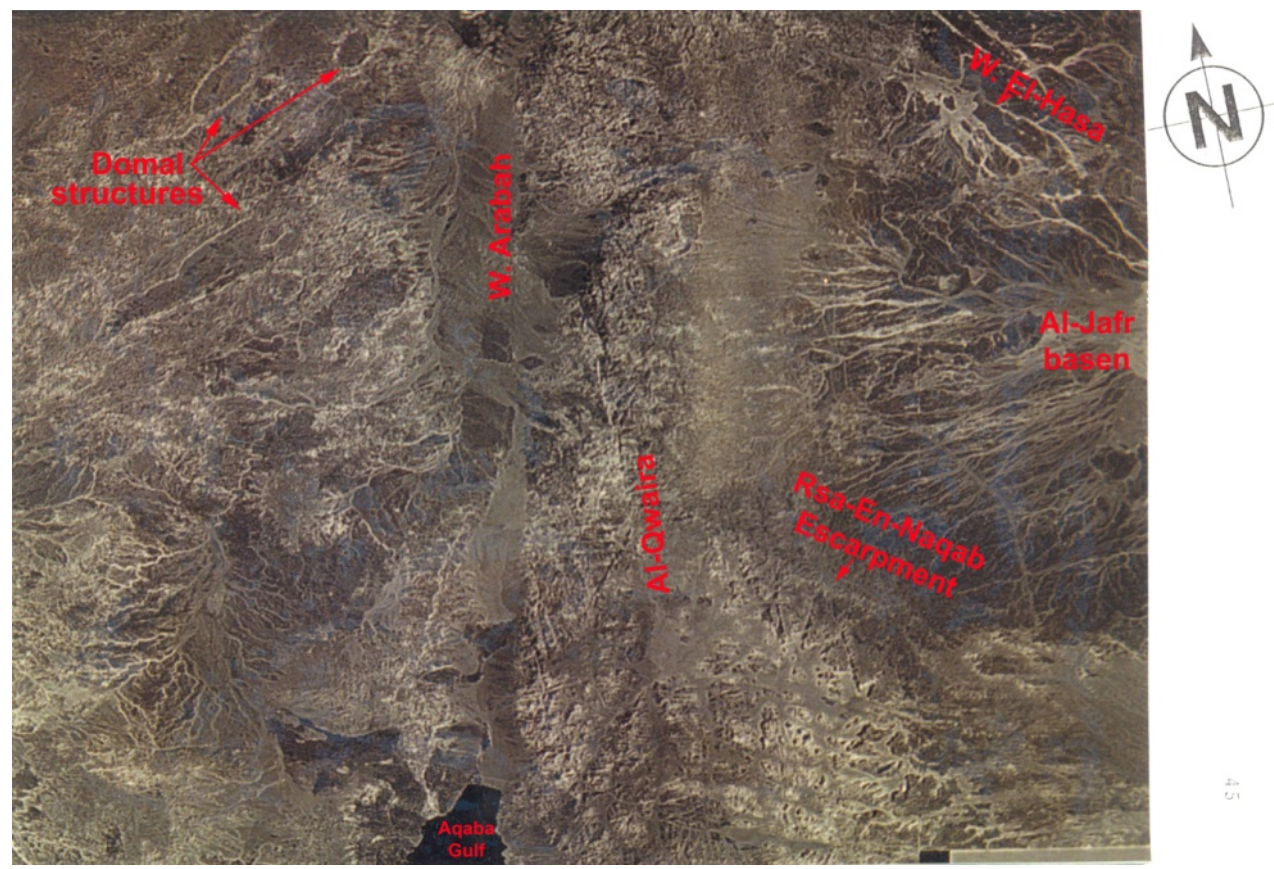

Figure 5. Filtered first principal component image of southwest Jordan. The geological features in the image are sharper than those in any other product. Lineaments are easily recognized in the image 


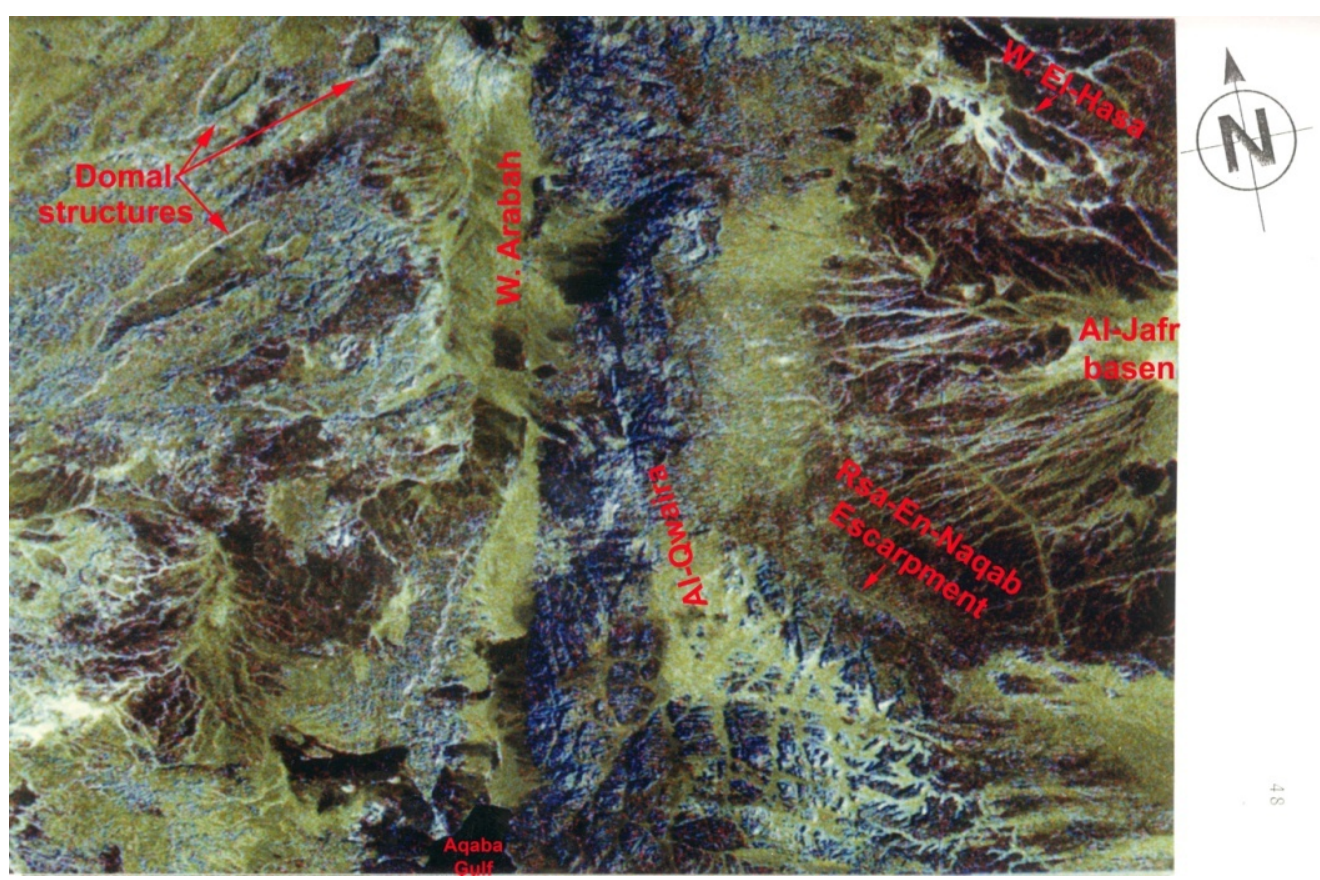

Figure 6. Image in which PC1, PC2 and FPC1 are combined, then assigned to H, S and I, respectively. Excellent results were obtained; lineaments, in particular those of east-west trend are clearly defined. Contrast produced by elevation differences also shows well. Basement rocks are distinguished by dark blue hue 